\title{
Learning About Water Management through the African Catchment Game
}

\author{
R. C. Fox ${ }^{\natural, ~ K . M . ~ R o w n t r e e}{ }^{1}$, R.Fox@ru.ac.za, K.Rowntree@ru.ac.za, L. Fraenkel ${ }^{1}$
}

\begin{abstract}
The African Catchment Game (ACG) is an innovative role-playing game for Geography educators that simulates a "real imaginary country". It enables the participants to explore how rural and urban stakeholders in southern African countries may, or may not, develop scenarios of sustainable water use. The ACG has been developed from Graham Chapman's the Green Revolution Game/Exaction of the 1970s and 1980s. Our modifications to Chapman's game are under-pinned by theories of Complex Adaptive Systems and educational approaches based on constructivist, active/experiential learning models. This paper examines the impact of two game runs through examining the experiences of the participants and managers of the game and analyzing empirical data collected during each game run. The African Catchment Game was played twice in Finland in 2008 as part of a collaboration intended to explore the possibilities of simulations being used as tools for predicting African futures. Our analysis shows that the participants' understanding altered and deepened as a result of playing the game. The nature of the game, as a Complex Adaptive System, and the use of a constructivist learning approach, means that the particular learning that took place cannot be extrapolated to more universal contexts, but the value of the learning process can be more generally applied.
\end{abstract}

Key words: African Catchment Game, Geography Education, Role Playing Games, Complex Adaptive Systems, Sustainability.

Recibido el 19 de abril de 2012, aceptado el 13 de junio de 2013.

Department of Geography, Rhodes University, South Africa, PO Box 94, Grahamstown, South Africa 6140 . 


\section{INTRODUCTION}

The African Catchment Game (ACG) has been adapted from Graham Chapman's Green Revolution Game that dates back to the 1970s (CHAPMAN 1987, 1989). The Green Revolution Game is a powerful educational tool for Geographers and resource managers that simulates modernization, the Green Revolution package of seeds, fertilizers, pesticides and irrigation technologies, amongst ricegrowing farmers in South Asia. Chapman made use of systems thinking, complexity theory and field data to develop this game. He saw a lack of conceptual understanding amongst students about farming decisions that called for a different teaching approach. His simulation game provided students with the opportunity to wrestle with the inter-relationships that are linked to the decision-making processes associated with developing farming strategies, particularly in relation to irrigation technologies. Subsequently the Green Revolution Game has been played in the United States of America (PARK et al 1995), the United Kingdom (CHAPMAN 2003, Personal communication), South Africa (FOX \& ROWNTREE 2004), Sweden and Finland (ROWNTREE et al. 2009). A later modification to the game added an urban sector, with industry, commerce and a government. This more complex game, called Exaction, was produced in collaboration with Elizabeth Dowler of the London School of Hygiene and Tropical Medicine (FRAENKEL 2010).

Chapman's Green Revolution Game (GRG) would fall within what WALFORD (1969, 1995) has described as the development and refinement stage in the use of games and simulations in Geography. Our own modifications to GRG fall within the final stage of acceptance and stabilisation that typically comes some 25 years after the first stage. The African Catchment Game
(ACG) models the southern African context and adds a number of new elements to the game including a dam, two different rainfall regimes, reticulated water supplies, livestock farming, debt, sustainable development and HIV-AIDS. For the 2008 simulations in Finland (FRAENKEL 2010), we developed new environmental components that were the foci for the subsequent analysis of the games. A dam and associated river system were used to facilitate understanding and appreciation of the inter-relationships between water management, food security and economic development. In this paper we analyse the two games that were played in Finland in 2008 from the point of view of the managers of the game and the participants in the game. The analysis examines global (macro-scale) game dynamics, local scale dynamics (at the farm or business level) and the network of interconnections revealed through the games.

Water and food, together with territory, raw materials and sources of energy are considered the five most prized natural resources (GLEDITSCH 1998). They are also central to the non linear, complex adaptive ways though which energy, climate and security may bring about conflict (HOMER-DIXON 2007). All of these are modelled within the ACG. Water is considered both a scarce and vulnerable resource in Africa and the world over, while agriculture is the largest sector dependent on this resource (HIRJI \& MOLAPO 2002, APPELGREN 2004). There is a need to balance two partly incompatible pressures in the ACG: human survival and the protection of the resource base on which humans depend (FALKENMARK \& ROCKSTROM 2004). In the ACG agents (the players of the simulation) develop schema in order to manage their resource use, but their policies and strategies are frequently undermined by haphazard economic and environmental fluctuations 
interacting with incomplete or partial information exchanges. These are just the type of interactions that lead to the multiple stresses that HOMER-DIXON (2007) shows may precipitate social collapse.

The need to conserve our natural resources, especially water in this instance, requires an understanding of the linkages between the social, political, economic and biophysical dimensions. These have been clearly drawn up by educators such as LOTZ-SISITKA \& RAVEN (2006) and O'DONOGHUE (2006, in LOTZ-SISITKA \& RAVEN 2006). Their presentation of the linkages was used as a framework (Fig. 1) against which we mapped the participants' changes of understanding that we collected using pre and post game questionnaires (FRAENKEL 2010).

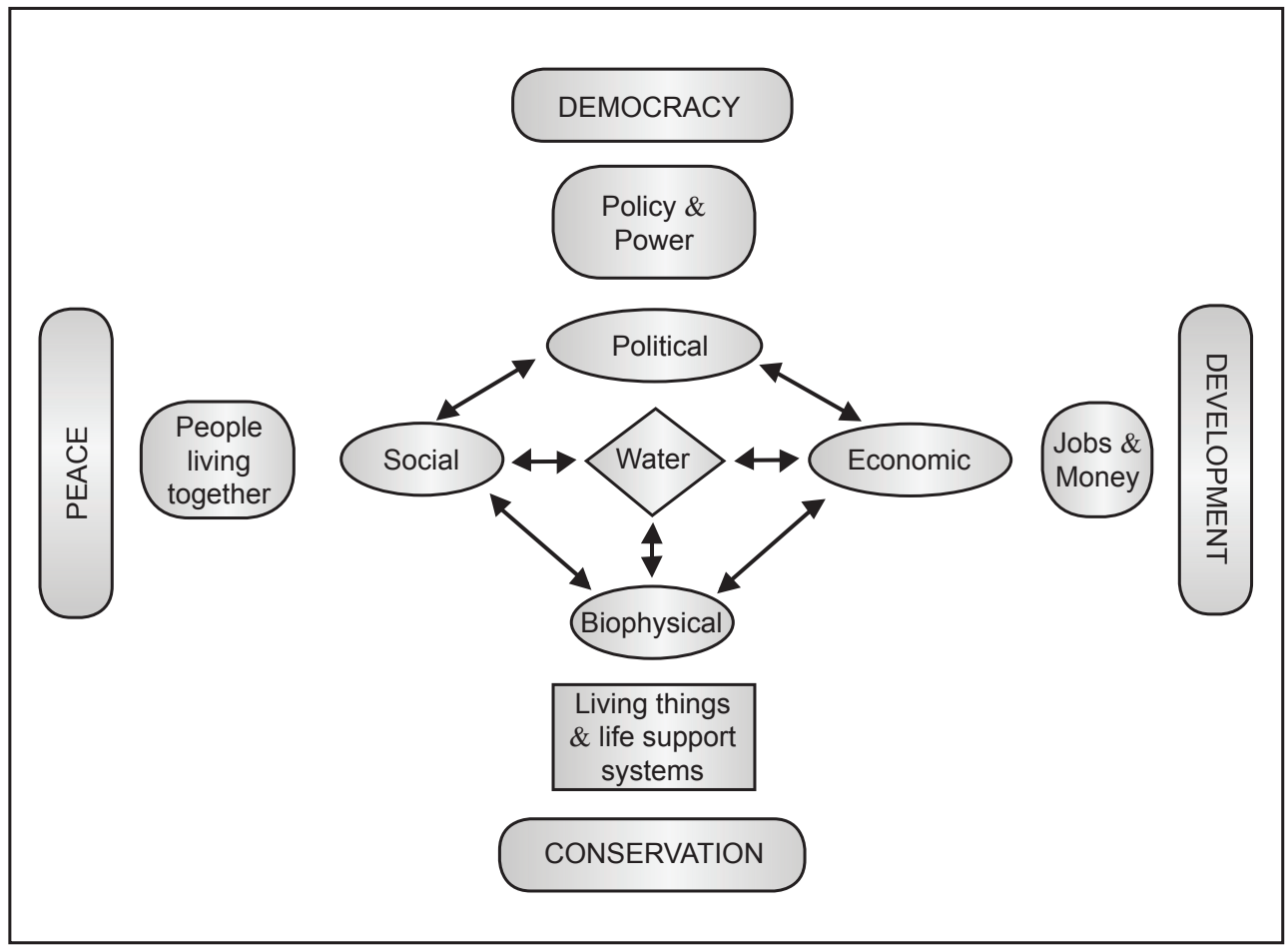

Fig. 1. Water positioned within four inter-related dimensions. Source: Adapted from O'DONOGHUE (2006).

The educational underpinnings of the African Catchment Game can be traced back to Piaget's constructivist theory of learning (MCINERNEY \& MCINERNEY 2006). This asserts that knowledge is not transmitted directly from one person to another through face-to-face teaching, but is rather built up by the learner through exploration and discovery. The learning process can also be seen as a social activity, following the ideas of Vygotsky (18961934), and is not limited to a solitary process. Social constructivism refers to how a learner constructs knowledge in a social context, such as a simulation game, by making personal meaning from 
socially shared perceptions. The student is an active agent, making meaning in his/her life and in so doing, constructing knowledge (DONALD et al. 2002) in a joint enterprise with the facilitator of their learning activities (ATHERTON 2005). By making links between new information and experience and the existing knowledge base, new knowledge is created. These links are either in the form of adding to, modifying, or reorganizing existing knowledge and/or skills. Unless one makes these links, the new knowledge remains isolated and is not used effectively for new tasks, or in new situations. The ability to encode information, as well as the retention and retrieval of information, is critical for effective learning.

Role-playing simulation games such as the African Catchment Game (ACG) allow students to construct their own knowledge through their experiences. In the past we have used reflection exercises as assessments (FOX \& ROWNTREE 2004) to ensure that understanding has been consolidated after the simulations. Typically, the reflections require participants to describe and reflect on what they have experienced and then connect this to theoretical literature or constructs. The simulations in Finland used a more sophisticated approach with pre and post game questionnaires designed to facilitate a Chi-Squared analysis of whether players' perceptions and understandings had changed as a result of playing the ACG.

In the years since Chapman first designed the GRG, the systems thinking which underpinned the game has evolved. The multidisciplinary field of Complex Adaptive Systems (CAS) has developed steadily from the mid 1980s and now embraces ideas of complexity and adaptation. The ACG has been continuously developed, from the early 1990s and, as WALFORD (1995) suggests, this has been through modifying an original game concept to new circumstances and contexts. Theoretically and methodologically we now can understand and analyse the games through using DOOLEY'S (1996) nominal definition of Complex Adaptive Systems. The principles described below and the different levels at which they operate help us to understand how very complex games such as the ACG operate.

A CAS operates through three principles:

- order emerges within the system but it is not predestined;

- change within the system is not reversible, its history cannot be repeated;

- outcomes cannot be predicted in a simple linear way from the components, agents and processes existing within the system.

Agents (role players in our simulations) operate within the system, adapting to their environment in positive and negative ways, developing schema for survival, growth or change. The strategies adopted and rules formulated by agents are, however, dependent on incomplete or biased information, while positive or negative multipliers can impact the flows of resources or information in the simulation, depending on the complexity of the system and who is connected with whom. Agents have tags that identify or encode their roles and these may be combined into aggregates or meta-agents. Examples of ACG meta-agents are the roles of President, Minister of Water and Minister of Home Affairs. There are also agents and meta-agents sitting partly outside the CAS who determine the rules of information and 
resource flows within the CAS. In the ACG these are the three game managers.

A Complex Adaptive System typically operates at three different levels (LEVIN 1998) and we will use these to structure the analysis of the impact of the games below.

- For the global level, through examining macro-level performance indicators collected by the managers (meta-agents) on spreadsheets as the simulation unfolds.

- For the local level, through the players (agents) telling us about their strategies and understandings (schema) in the pre and post game questionnaires.

- At the network level where both the managers (as participant observers) and players reflect on the selforganization of the simulation, who was connected with who, where resources and information came from etc. This is aided by photographic and video recording.

The analysis in this paper starts with the global levels, moves on to examination of the local and ends with some supplementary information at the network levels.

\section{MATERIALS AND METHODS}

The ACG was played twice in Finland between 3 and 5 June 2008 at the Finland Futures Research Centre (FFRC), Turku and subsequently at Tammela as part of the Futures Summer School 'systems and simulations': a full description of the operational characteristics of these game runs is given in ROWNTREE et al. (2009). The 23 participants in the Turku simulation were futurists: the staff and students of FFRC. $78 \%$ had completed Higher Degrees and the remaining 22\% were still completing their Higher Studies. The 28 participants at the Tammela game were more mixed in background with civil servants, designers and teachers making up 20\% and a further $33 \%$ being students. Fewer had already completed Higher Degrees $(46 \%)$. There were three game managers. The first managed the urban sector and mediated global trade, the second managed the rural sector and the third managed the allocation of water resources to both the urban and rural sectors. Each manager kept a spread-sheet capturing the dynamics of the production, consumption and trading of materials (including water) through the duration of the game. The managers also kept photographic and video records of the game runs. The data from the managers' spread-sheets were used, with the video record, to assess the global level, macro scale, game processes.

The participants completed_pre and post game questionnaires concerning the following aspects of water and water management in southern Africa:

1. How is water used?

2. Who controls water use?

3. Identify and explain the issues and challenges associated with water management.

4. Why do you think these issues and challenges have emerged?

5. In the post game questionnaire they were also asked to comment on:

6. How and whether the game has helped their understanding of water management. 
7. Whether they could use insights gained from the game.

8. Recommendations for improving the game.

Participant's responses to each question were allocated to four or five categories, the social, political, economic and biophysical dimensions in figure 1, and 'other' when appropriate. In order to see if there was any statistically significant change between pre and post questionnaires we used the ChiSquared test on the resulting four (or five) by two matrices. In this way we identified any change in participants' knowledge as a consequence of playing the game.

Finally, we collected network level information from the debriefing workshop held after the Turku game. Through a discussion-based process, participants identified key links experienced through the game between the components in the model presented in figure 1. Time constraints, unfortunately, meant that we did not have the opportunity to repeat this operation after the game in Tammela.

\section{RESULTS}

The following section sets the scene by describing and interpreting the significance of the simulation-wide (global) processes. Our game managers' spreadsheets, which captured the macro-scale economic, trade, population, production, consumption and environmental processes, were used for this.

\section{Turku and Tammela games: description of global processes}

\section{The Turku game}

There were 23 participants in the Turku game run: they were well qualified, mostly Finnish, speaking English as a second language and either working or studying in the Higher Education field. Nearly two thirds were female and most were aged between 26 and 40 years.

Above average rainfall was experienced during the four year game run and this resulted in low water prices and, in the third yearly cycle, a mild flood that irrigated one field per farm. Food security was not an issue in the game run as a whole due to the doubling of the total yield of rice. Yields increased in line with the total population's growth that resulted in figures that were six percent higher at the end of the game. Urban productivity, however, was hindered by the inefficiency of the industrial sector, which was unable to master the input and output processes of the factory system. This resulted in a negative trading balance in the second yearly cycle. The farmers, however, managed to export their surplus rice and so rice exports had tripled by the fourth yearly cycle resulting in an overall favourable trading balance in years three and four. Debt from building the dam to regulate water flows remained an issue for the government until the bank was nationalized and so eliminating all relevant debt. Money that would have been spent on paying back the dam loan was then used to subsidise the farming industry, consequently aiding the production of rice surpluses.

\section{The Tammela game}

The 28 Tammela Game Run participants were mostly female Finnish students who had obtained their second degree and were completing their Masters' degree. The majority of these players spoke English as their second language and played the ACG as part of the summer school programme organised by the Finland Futures Research Centre.

Although rainfall remained constant throughout the game it was considerably 
less than in the Turku game run. Total population increased by $15 \%$ over the fouryear game period and this resulted in rice consumption exceeding rice production throughout the game. Farmers therefore needed to secure agricultural water for irrigation and, as a result, the government issued more agricultural and domestic water than industrial water. The peasant farmers formed a commune that allowed them to share their limited resources and to meet the demand for food and water. Since peasant farmers were working together as a group, their negotiations with government were effective in procuring subsidies. This left the other game players in the rural sector, such as the commercial farmers and the trader, without government aid, forcing them to consider alternative income strategies. One such strategy included allowing children to starve to death, as they had become a liability. In the urban sector, the government initially focused industrial support on getting sustainable sources of water installed before the industrial production process was properly understood. This resulted in extreme fluctuations between a positive and negative trading balance. In terms of urban productivity, imports significantly decreased throughout the game, while exports increased. Although food security was sustainable, factories were not reliably run and this contributed to the fluctuating trading balance.

\section{Turku and Tammela games: analysis of local processes}

The changes in players understanding are revealed through comparison of responses in the pre and post simulation questionnaires. Table 1 summarises the statistical results of the Chi-Squared tests undertaken on data combined from the two game runs: it wasn't possible to get valid statistical results on each separate game run as there were an insufficient number of participants. The table 1 shows, for example, that the most statistically significant response came for the question: identify and explain what issues and challenges, if any, are associated with water management? The 51 participants (23 for Turku and 28 for Tammela) responded to this question in different ways after they had played the African Catchment Game. The simulation had, accordingly, altered their awareness of water management issues through immersing them in the role playing process.

TAble 1. Statistical ANALYSis COMPARING RESPONSES FROM THE PRE AND POST SIMUlation QUESTIONNAIRES (FRAENKEL 2010).

\begin{tabular}{|c|c|c|c|}
\hline Question & Chi Square & Significance & $\begin{array}{c}\text { Degrees of } \\
\text { Freedom }\end{array}$ \\
\hline $\begin{array}{c}\text { Identify and explain what issues and challenges, if any, } \\
\text { are associated with water management? }\end{array}$ & 25,21 & $>0.001$ & 4 \\
\hline How is water used (in a southern African context)? & 20,50 & $>0.001$ & 3 \\
\hline Who controls water? & 15,89 & $>0.001$ & 3 \\
\hline $\begin{array}{c}\text { Why do you think these issues and challenges have } \\
\text { emerged? }\end{array}$ & 10,17 & $>0.025$ & 3 \\
\hline
\end{tabular}

The following short sections examine, in descending order from highest to the lowest, each of the questions with highly significant Chi-Squared values (probability $>0.001$ ). 
1. Please identify and explain what issues and challenges, if any, are associated with water management. (Chi-Square $25,21)$.

For both the Turku (52\%) and Tammela (56\%) game runs the highest response rates in the pre-game questionnaires came in the Political Dimension. This was maintained in the post-game questionnaire with very minor changes. Responses relating to the Biophysical Dimension declined in both game runs from 20 to $13 \%$ in Turku and from 24 to $22 \%$ in Tammela. The Economic Dimension became more important, however, increasing sharply from 4 to $23 \%$ in Turku and, less spectacularly, from 15 to $19 \%$ in Tammela.

Themes repeated in both game runs included climate change, droughts and pollution. New themes in Turku can be grouped under vulnerability: focusing on the political, economic, social and biophysical aspects that drastically impact on survival. Also there were themes categorised as future considerations that make note of significant political, economic, social and biophysical aspects that need to be addressed. The Tammela post-game themes can also be grouped, but this time into four sub-headings: government regulated issues, natural resources, ability to work together and other. In addition, themes tended to acknowledge practical issues and challenges, which can account for the heightened sense of personalisation and urgency in the post-game themes, whereas the pre-game themes seem more abstract, hierarchical and devoid of agency.

2. How is water used in the southern African environment? (Chi-Square 20,50).

For the Turku game run responses within the Economic Dimension dominated in the pre and post game questionnaires ( $41 \%$ and $56 \%$ ), followed by the Social Dimension (24\% and 22\%). In Tammela the Political Dimension had the highest pregame response rate $(53 \%)$, but this declined sharply in the post-game questionnaires to $2 \%$. The Economic Dimension went up from 33 to $65 \%$ and the Social from 3 to $32 \%$.

The Turku pre-game themes focused on the use of water for agriculture and industry, acknowledging that water is scarce and should be used sparingly in both social and domestic contexts, while the Tammela pre-game themes focused on access, be it due to economic, historical or infrastructural and political reasons. The Turku post-game themes focused on how expensive water is and its important water for survival as well as on how chance plays a significant role in survival strategies. The Tammela post-game themes included a focus on the participants' immediate domestic surroundings and non-immediate surroundings: government management and the use of water as a trading commodity. In addition, there was a heightened sense of urgency and, perhaps, desperation, since participants realised through playing the game that water is crucial for survival. There was a noticeable shift between the pre- and post- questionnaires from the use of water in an immediate geographical context to include non-immediate uses, as well as the acknowledgement that water is important for survival.

3. Who controls water in southern Africa? (Chi-Square 15.89).

In both the Turku and Tammela game runs, the Political Dimension received the highest response rates for the pre- and post-game questionnaires. Political agents and the government control of water were important common themes. In Turku, the Political Dimension increased from 48 to $59 \%$ as there 
was a shift away from the Other Dimension into the Political and also, as mentioned below, into the Biophysical. In Tammela the Political responses increased from 68 to $83 \%$, this was matched by a corresponding decline in the Economic from 24 to $13 \%$ and the Social from 5 to $0 \%$.

In the Turku game run participants' opinions of water control changed from ownership and management, as agents of control, to Biophysical aspects, pricing, misinformation and complexity. This infers that participants had acknowledged the interconnected impacts of water control. Participants from the Tammela game run showed a shift in their understanding of water control from a general to a more centralised focus, including all environmental dimensions and incorporating economic agents and reasons.

\section{Network analysis of the Turku game}

The participants' view of the interconnections between the environmental dimensions of water can be done for the Turku game run by looking at the graphic drawn during the debriefing (Fig. 2). Unfortunately, there was not the time during the summer school to debrief the Tammela participants so there is no direct comparison. The diagram was drawn by one of the game managers whilst the other two managers facilitated discussion concerning the network connections with the participants. Figure 2 shows that there is an obvious focus on the connectivity of society with the political and economic dimensions: this was almost certainly a reflection of the strong social cohesion in the Turku game that the managers' also experienced.

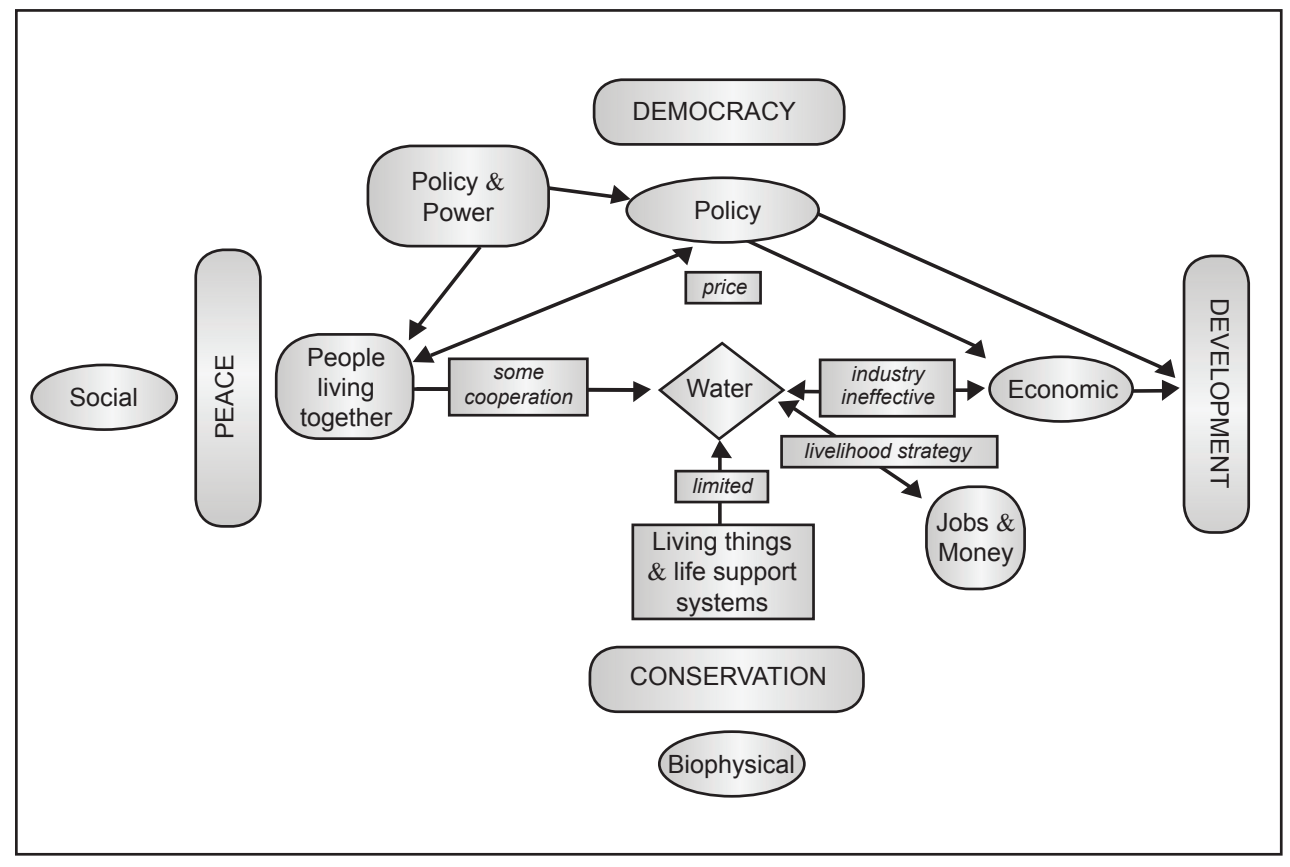

Fig. 2. Dimensions of water work-shopped with Turku participants. 


\section{DISCUSSION AND CONCLUSIONS}

The global scale analysis showed that even though the starting parameters of the two games were very similar the stochastic elements built into the game combined with the players' own strategies produced different macro scale phenomena. The Turku game was, in one sense, easier for the participants as there was sufficient rainfall for food security and their population grew at a sustainable rate. In contrast the Tammela game was food insecure since their population grew at a high rate. This led to deaths - some of them a direct consequence of the participants deliberately not strategizing appropriately. A valuable discussion was drawn out here in the post game workshop since many southern African countries also have policies of inaction - waiting for food aid - that results in starvation of those most vulnerable in society: children and the elderly. In the Turku game the government was innovative in nationalising the country's bank: this rapidly reduced their level of debt and meant that there was funding to support agriculture. In the Tammela game the peasant farmers formed a commune and pooled all of their land, labour, livestock, seed, pesticides, fertilisers and water allocations. They, therefore, became a powerful force in the game and managed to get subsidies from the government.

At the local level the Chi-Squared analysis showed that the game participants' understanding of the role of water, water management and water issues was clearly impacted through playing the game. The three most significant responses were in relation to the water management issues and challenges, how water is used and who controls water. The manner in which participants increased their understanding of water management was with reference to their own experience and pre-existing knowledge. Coming from the Nordic region, which is a water rich region of the world, the participants were usually challenged by how difficult it is to manage water use when it is a scarce and unreliable resource with the various sectors of the economy competing strongly for allocations.

The ACG can be understood as a Complex Adaptive System and our analysis has used this to structure the results given above. Furthermore, our analysis has shown that playing the ACG is a successful way of promoting the construction of new knowledge. The participants were almost all from the Nordic region and very well educated, however, they were unfamiliar with the southern African context (particularly the scarcity of water). For them the interplay of environmental, social, economic and political forces presented formidable challenges which they managed, at least in part, to overcome and learn from.

\section{ACKNOWLEDGEMENTS}

The authors would like to thank the National Research Council for research funding (FA2006041000021 Modelling Political Geoecology) and the CIMO/ North-South-South project (FinnishSouth-African GAME - the Foresight Game as a tool for generating futures images 2007-2009) for funding exchanges between Finland Futures Research Centre and Rhodes University. The comments of anonymous referees have helped us clarify the issues examined in the paper. 


\section{REFERENCES}

APPELGREN, B., 2004. Ethics and water: water in agriculture. UNESCO, Paris. 39 pp.

ATHERTON, J.S., 2005. Learning and teaching: experiential learning. Available http://www.learningandteaching.info/ learning/experience.htm.

CHAPMAN, G.P., 1987. Gaming simulations and systems analysis: two factions of the truth. Journal of Applied Systems Analysis, 14: 3-15.

CHAPMAN, G., 1989. Developing real imaginary countries. Irrigation and Drainage Systems, 3: 309-313.

CHAPMAN, G., 2003. Personal communication during an interview concerning the development of the game, November 21st, Lancaster University, Lancaster, England.

DONALD, D., S. LAZARUS \& P. LOLWANA, 2002. Educational psychology in social context. 2nd ed. Oxford University Press, Cape Town. 368 pp.

DOOLEY, K., 1996. Complex Adaptive Systems: a Nominal Definition. Available http://www.eas.asu.edu/ kdooley/ casopdef.html.

FALKENMARK, M.\& J.ROCKSTROM, 2004. Balancing water for humans and nature. Earthscan, London. 247 pp.

FOX, R. \& K. ROWNTREE, 2004. Linking the doing to the thinking: using criterion-based assessment in role-playing simulations. Planet, 13: 12-15.
FRAENKEL, L., 2010. Learning about water through the African Catchment Game: the refinement of a role playing simulation game. Unpublished MA thesis, Rhodes University.

GLEDITSCH, N.P., 1998. Armed conflict and the environment: a critique of the literature. Journal of Peace Research, 35(3): 381-400.

HIRJI, R. \& J. MOLAPO, 2002. Environmental sustainability in water resources management: a conceptual framework. En: HIRIJI, R., MARO, P. \& MATIZA CHIUTA, T. (Eds.) SADC technical report: Defining and mainstreaming environmental sustainability in water resources management in Southern Africa. SADC, IUCN, SARDC, World Bank, Maseru/Harare/Washington DC. pp. 1-20.

HOMER-DIXON, T., 2007. Conflict in a non-linear world: complex adaptation at the intersection of energy, climate, and security. Available http://www.homerdixon. com/2007/04/25/conflict-in-a-nonlinearworld/

LEVIN, S.A. , 1998. Ecosystems and the biosphere as complex adaptive systems. Ecosystems, 1(5): 431-436.

LOTZ-SISITKA, H. \& V. RAVEN, 2006. Active learning in OBE: environmental learning in South African schools. Report on the National Environmental Education Programme - GET Pilot Research Project, Department of Education, South Africa. $119 \mathrm{pp}$. 
MCINERNEY, D.M. \& V. MCINERNEY, 2006. Educational psychology: constructing learning. Prentice-Hall, Australia. 541 pp.

PARK, W.M., B.C. ENGLISH, M.D. GRAY \& C.L. CLELAND， 1995. Experiential learning through participation in green revolution/exaction: a role playing simulation. Review of Agricultural Economics, 17: 257-265.
ROWNTREE, K.M., L.A. FRAENKEL \& R.C. FOX, R.C., 2009. Exploring risk related to future climates through roleplaying games: the African Catchment Game. En: KOSKELA, M., \& VINNARI, M., (Eds.) Future of the Consumer Society. FFRC eBooks 7/2009, Turku School of Economics, Turku, pp. 210-221.

WALFORD, R., 1969. Games in Geography. Harlow: Longman. 131 pp.

WALFORD, R., 1995. A quarter-century of games and simulations in Geography. Simulations and Gaming, 26(2): 236-248. 